\title{
Publisher Correction: Theory-guided design of catalytic materials using scaling relationships and reactivity descriptors
}

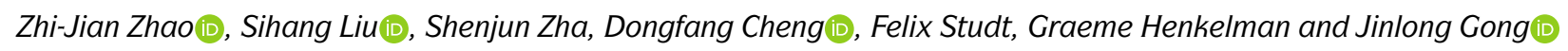

Nature Reviews Materials (2019) https://doi.org/10.1038/s41578-019-0152-x Published online 21 November 2019

In this Review Article, the accept date was inadvertently omitted. It should be 15 October 2019. This error has been corrected online.

https://doi.org/10.1038/s41578-020-0192-2 I Published online 9 March 2020

(c) Springer Nature Limited 2020 